apportait, par la sûreté de son jugement et sa haute culture; un précieux concours.

Nous sommes assurés, Messieurs, que vous vous associerez à notre deuil, particulièrement ceux d'entre vous qui, aux Conférences internationales de'Genève, Carlsruhe, Rome Vienne, Saint-Pétersbourg et Londres, ont eu l'occasion d'apprécier la compétence et les connaissances étendues de notre regretté collègue, toujours alliées, chez lui, à une modestie réelle et à une parfaite courtoisie.

C'est dans ces sentiments, que nous vous prions d'agréer l'assurance de notre considération la plus distinguée.

Pour le Comité international de la Croix-Rouge:

Le président,

Gustave Ador.

\title{
Le Colonel Camille Favre
}

\section{(Nécrologie)}

Le Comité international vient de faire une perte irréparable en la personne de son vice-président, $M$. le colonel Camille Favre. On remplace difficilement des hommes qui, comme lui, ont assisté à la fondation et aux débuts de l'ouvre de la Croix-Rouge, qui l'ont vue grandir et s'implanter peu à peu sur toute la surface du globe, malgré les hostilités et les obstacles. Ces hommes-là étaient dignes à tous égards de tenir avec d'autres les rênes du Comité in. ternational fondateur de cette noble institution.

Né en 1845, d'éducation militaire, par la famille dont il ètait issu comme par ses goûts personnels, il avait, en 1870-71, fait partie des troupes suisses envoyées à la frontière lors de l'internement de l'armée de l'Est, et bien que s'étant retiré du service actif après avoir commandé une brigade d'infanterie, il a continué à porter à l'armée suisse tout son amour, toute son admiration, mettant 
tout son enthousiasme aussi à la défendre avec les compétences et les expériences qu'il s'était acquises.

Il possédait, à côté de cela, une large culture. Elève de l'école des Chartes, de Paris, il avait obtenu le grade d'archiviste paléographe. Il collaborait à plusieurs journaux, et écrivait de fortes études, documentées et bien pensées sur les sujets militaires. L'Angleterre, sa politique et son armée, était un champ d'étude pour lequel il avait une pré dilection particulière.

Grand amateur l'art, et connaisseur en cette matière. il était l'àme de la Société auxiliaire du Musée d'art et d'histoire, à Genove; c'est lui qui avait organisé, avec le plus grand succes, le groupe de l'art ancien à l'Exposition nationale suisse de 1896.

"Sa culture générale si étendue, dit le Joumul de Genève". sa connaissance des pays et des gens, ses relations avec les hommes politiques de l'étranger faisaient de lui un conseiller précieux. Dans les questions nationales on aimait a suivre ses directions qui s'inspiraient toujours d'un zèle ardent pour le bien public, d'un amour enthousiaste de la cité, d'un sentiment très noble et très profond de la patrie ".

Et le colonel Ed. Secrétan, directeur de la Gazette de Lausanne, après avoir retracé sa carrière militaire, ajoute : "Cet officier d'état-major savant, cet homme dont l'histoire et l'art de la guerre ont été l'étude favorite, n'était d'ailleurs pas qu'un militaire. Tout ce qui touche à la vie nationale, à la politique internationale, au gouvernement des peuples sollicitait au plus haut degré cet esprit d'une culture haute et étendue et dont la distinction était rehaussée par la plus parfaite modestie. Il était informé de tout dans le domaine des lettres et des arts et consacrait sa fortune et ses loisirs à seconder tous les efforts pour l'accroissement de la culture générale. »

On comprend qu'un homme comme lui, avec son esprit largement ouvert et richement cultivé, fût précieux au

No du 11 janvier 1914. 


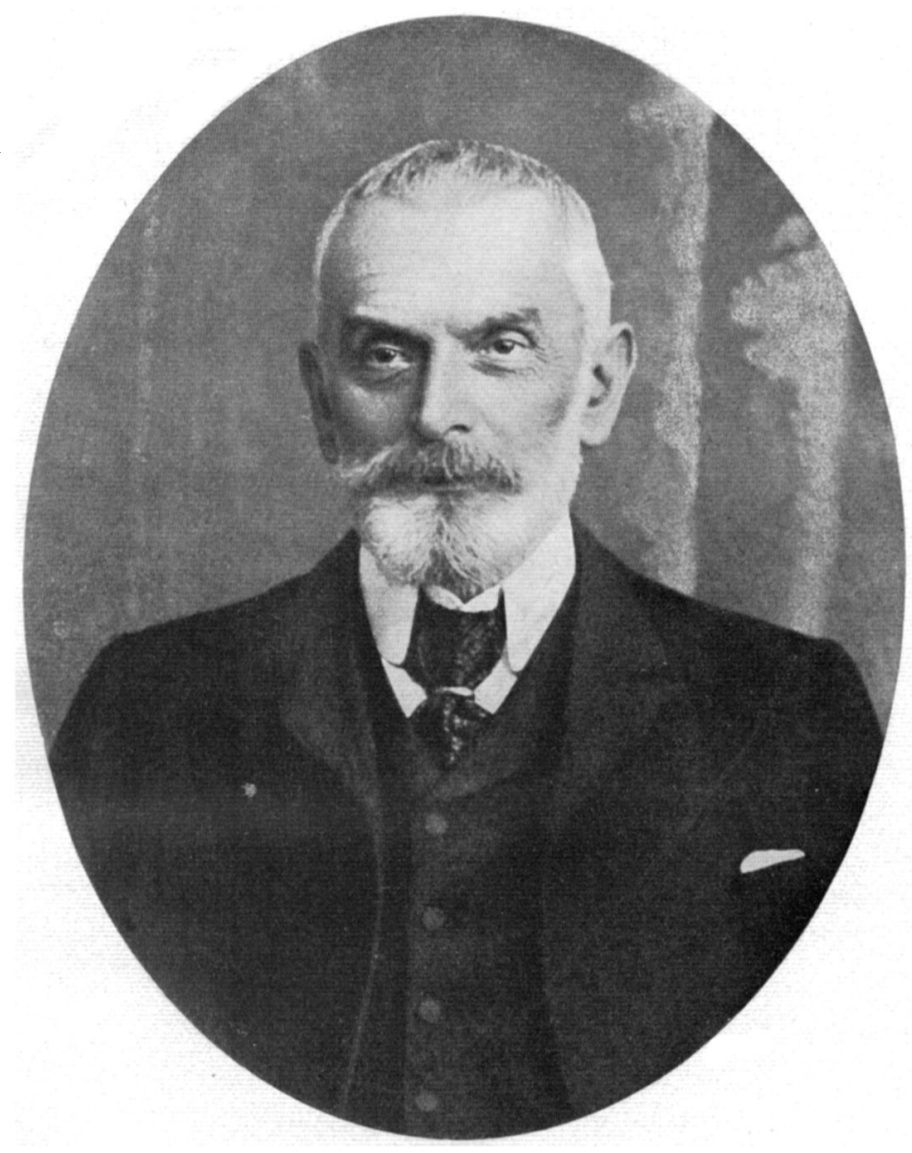

Colonel Camille Favre

Vice-Président du Comité international de la Croix-Rouge décćdé le to Janvier IgI4 
sein du Comité international, à la tâche duquel il apportait l'appui de ses connaissances étendues et la sûreté d'une éducation distinguée et d'un tact parfait. Il y était entré déjà le 22 décembre 1883, succédant après trois ans d'intervalle à son père, le colonel Edmond Favre, qui en avait fait partie de 1867 jusqu'à sa mort. En 1912, il avait été appelé à y revêtir la charge de vice-président, concurremment avec M. le ministre Ed. Odier, que ses fonctions retenaient à Saint-Pétersbourg. En 1887, il présenta à la Conférence internationale de Carlsruhe, au nom du Comité international, le rapport dont la Conférence de Genève de 1884 avait chargé ce dernier, sur le projet de monument à élever à la Croix-Rouge à Genève, conçu par le sculpteur zurichois Kissling. On sait - et on peut le regretter pour la ville qui lut le berceau de la Croix-Rouge - que ce monument ne fut jamais exécuté.

Camille Favre suivait de très près, avec un intérêt actif et une sollicitude constante, tout ce qui touchait à la tâche du Comité international et se préoccupait des questions délicates qui lui étaient parfois soumises. Il prit part aux Conférences internationales de Genève, de Carlsruhe, de Rome, de Vienne, de Saint-Pétersbourg et de Londres. Il fit partie, notamment à cette dernière, de la commission des félégués, comme représentant du Comité international. La Conférence de Washington, à laquelle des circonstances personnelles l'empêchèrent de se rendre, fut la seule qu'il manqua. Ceux qui ont eu le privilège de le rencontrer, dans ces assises internationales, se souviendront de la compétence de ses avis, de son jugement sûr, du concours que ses connaissances étendues et son expérience des choses, apportaient aux délibérations, en même temps que de la constante bonne grâce de son accueil, de la réelie modestie de son attitude et te l'exquise courtoisie de ses manières qui étaient celles l'un parfait gentilhomme.

Les Sociétés nationales de la Croix-Rouge comprendront les regrets profonds du Comité international à se voir privé prématurément du concours éclairé et dévoué de cet homme de bien, de cet ami fidèle, toujours empressé à rendre ser- 
vice. Elles s'associeront à son profond chagrin, de même que les collègues de Camille Favre prennent une part personnelle à la douleur des siens.

\section{Rapport annuel sur la situation du fonds Augusta}

En conformité de la décision prise quant à l'attribution des revenus du Fonds Augusta en juin 1913 (voy. notre circulaire $n^{\circ} 146$ du 7 janvier 1913, T. XLIV, p. 14), les frais de la mission de M. de Marval sur le théâtre de la première guerre batkanique ont été prélevés sur ces revenus.

Ces derniers étaient, au 7 janvier 1913, de fr. 10.900,25.

Les frais de cette mission ont été de fr. 6.300 .

Au 7 janvier 1914, le Fonds Augusta restait composé de :

Fr. 53.000 , obligations $3 \frac{1}{2} \%$ Emprunt suisse des chemins de fer.

Mk. 40.000 , obligations $3 \frac{1}{2} \%$ Consolidé prussien.

A la même date il présentait un solde disponible de fr. $8.263,15$.

\section{Félicitations}

\section{à l'occasion du cinquantenaire de la Croix-Rouge}

Sous le titre : Il y a cinquante ans, nous avons rappelé ${ }^{1}$ que, du 26 au 29 octobre 1863, s'était réuni à Genève la Conférence internationale qui a fondé l'institution de la Croix-Rouge.

A cette occasion, nous avons reçu l'aimable message télégraphique suivant :

Kief, 29 octobre 1913.

Comité international de la Croix-Rouge, Genève

"La Socièté des juristes à Kief envoie ses félicitations à

' Voy. T. XLIV, p. 273. 